\title{
THE IMPACT OF PERSON-JOB FIT, PERSON- ORGANIZATION FIT ON JOB SATISFACTION
}

\section{Sheeraz Shah ${ }^{1}$ and Mehlab Ayub ${ }^{2}$}

\begin{abstract}
It has been observed in many organizations that some employees feel unsatisfied with their work, the justification behind the dissatisfaction could be due to various reasons such as skills and abilities of an employee if not match with the job or task requirements or the work assigned is not according to individual capabilities. As far as the previous studies are concerned, it is revealed that person job fit, and person organization fit have a significant positive relationship with job satisfaction. Thus, in this regard, this study was conducted to examine the relationship between person-job fit, and personorganization fit on job satisfaction. To gather the primary data, a questionnaire was adopted from previous similar published studies. The data were collected from employees working at Aspin Pharma, a pharmaceutical company in Karachi, Pakistan. The total number of study sample was 313 employees out of which 173 useable responses were employed for data analyses. In addition, this research study has adopted a descriptive survey design, and which utilized primary data to obtain information on the study variables. The method of the research is mono method, and the examination of the study is based in quantitative research through descriptive statistics to measure the multidimension of employee satisfaction, person job fit, and person organization fit. To conclude, the result reveals that Person Job Fit as well as Person Organization Fit have a significant relationship with job satisfaction. The study findings will be useful for managerial decision makers to improve person job and organization fit dimensions in their organization to enhance employee satisfaction and work productivity.
\end{abstract}

Keywords: Person-Job Fit, Person-Organization Fit, Job Satisfaction.

Benazir School of Business, Benazir Bhutto Shaheed University, Karachi, Pakistan 


\section{INTRODUCTION}

The idea of Human Resource Management (HRM) was firstly shaped during the 19th century. HR is defined as a term to manage employees in working field but now in the 21 st century the domain of HR has become massive with the disruption of technologies which has changed the firm level operations and production possibilities. Basically, the motive of HR is to manage people in an organization as well as to adopt a consistent approach of managing organization for long term sustainability in order to make production smooth. Human Resource system consists of HR strategies, HR policies, process, practices and programs. HR system can be created through organizational competencies to permit HRM and industries to enhance business opportunities. It is generally working faculty of any firm in limelight stage where it plays vital role to bring Human potential for production. The first goal of HR is enhancing worker's potential, recruit and select best employee for the organization and make firm's production effectively. HR must not compromise the quality of observe and determined best and massive characteristics in employees. Training of new employees is basic and most important goal of HR to make workers/ employees best for organization. Diversity plays a major role in the organization. Old and can't help organization in better way, means the goal of HR is to accept the diversity or change. The goal and duty of HR is enhancing main potential and make suitable relationship between organizations, employees and retain them.

Aspin Pharma in 2015 associated with OBS group, acquired Janssen, the pharmaceutical division of Johnson Pakistan in the year 2015. Aspin pharma claims to build establishment of its own identity, now pharma has achieved scale of efficiency with GNP complaint manufacturing facility and a team of dynamic professional has 313 employees across of its location. It has annual revenue of $\$ 15.29$ million and annual turnover rate is $700 \mathrm{~m}$. The growing at the rate of $15.7 \%$ and industry growth of $14 \%$ for the same period whereas, over all pharmaceutical industries in Pakistan, today, above 700 pharmaceutical firms send out 
products gain $\$ 200$ \$million to over 60 countries, growing at the rate of $12 \%$ and facing $20 \%$ employee turnover.

\section{Person Job Fit}

Person-Job Fit is a very important aspect because it can become a reason of higher performance, greater satisfaction, Lowe absenteeism, turnover, more organization citizenship and less stress too. The strong person job fit can be the reason to maximize the benefits for both employees and organization. Conditionally, the fit has a weaker job fit then organization is expected to face high turnover, absenteeism along with lower employee morale and production. The good match between employee Knowledge, Skills, abilities (KSAs), attitude and job requirement will lead to high job satisfaction. As the researchers revealed satisfied employee tend to be more productive and have positive significant relationship together. (Iqbal, 2012) (Farooquia \& Nagendrab, 2014).

\section{Person Organization Fit}

Person-Organization Fit means that how well the person fit with the organization culture. The culture of organization matters when a person is applying for a job in the selection process it is essential that applicant must be familiar with your company's culture because some candidate might have necessary competences to do particular task or job but yet not fit in with a company's culture. Person-Group Fit refers when employee work effectively with coworkers and supervisor, means, individual contentment with work groups, styles, skills and goals. It helps to improve job satisfaction, employee retention in organization and organizational commitment. However, person-organization fit is all about the fit among person values, culture, norms, personality and organization norms, values and culture. The influence of this fit is important for organization outcomes, job performance, organization commitment and job retention (Mao, 2014). 
To conclude, recent studied reviewed the relationship between Person-Job fit and Job satisfaction. A strong person job fit maximizes the both employee and the organization. Grounded in these domains above, this study investigates the relationship between $\mathrm{p}-\mathrm{j}$ fit, $\mathrm{p}-\mathrm{o}$ fit and job satisfaction.

\section{Job Satisfaction}

Basically, there are many reasons of job satisfaction by which the employee can be motivated and give $100 \%$. Some of these are offering incentives, crafting, a friendly and respectful environment and engaging them in challenging projects. Some cause of job satisfaction. 1) Good fit organization fit, 2) interesting and satisfying work, 3) rewards and incentives, 4) low stress environment. Most of time organization focuses on need fulfilment of employee which becomes a reason of employee satisfaction and employee will work according to the expectations and need.

\section{Industry Brief}

Aspin Pharma in 2015 associated with OBS group acquires Janssen, the pharmaceutical division of Johnson Pakistan in the year 2015. Initially start working with eleven original brands of Janssen like Motilium, Vermox, Imodium and Sibelium. Furthermore, we have penetrated into modern categories like cardiology, neuropsychiatry, endocrinology, nutraceutical, and women health, moreover, serving millions of patients.

\section{RESEARCH PROBLEM}

It has been observed in many pharmaceutical firms that employees feel unsatisfied with their work the reason behind could be various could be skills and abilities are unmatched with the Job requirement or the work is assigned is not according to the capabilities or the cultured and values are unmatched with employee culture. Late payment, Disrespect, Lack of appreciation 
leads to employee dissatisfaction. In this regard, the firm faces the high turnover intention, those who are unsatisfied will indirectly impact on production, therefore, the research investigates the association among person-job fit, person-organization fit and job satisfaction and impact of $\mathrm{p}-\mathrm{j}$ fit and $\mathrm{p}-\mathrm{o}$ fit on job satisfaction.

\section{RESEARCH QUESTIONS}

RQ1: Is there any significant relationship between person-job fit and employee job satisfaction?

RQ2: Is there any significant relationship between person-organization fit and employee job satisfaction?

\section{RESEARCH OBJECTIVES}

- To identify the relationship between person-job fit and employee job satisfaction

-To identify the relationship between person-organization fit and employee job satisfaction

In this respect, the survey questionnaires were adopted from previous studies. To measure the job satisfaction a three-item variable was adopted from the study by Spector (1985).. Moreover, to measure the independent variables person- job fit and person-organization fit questions were adopted from the study conducted by (Chhabra B. , 2015) For PJ-Fit a three (03) items scale was employed whereas for PO-Fit six (06) items were used in the questionnaire.

\section{LITERATURE REVIEW}

Job satisfaction is defined as the one's feeling it could be negative and positive or condition of mind towards one's job or the nature of work. (Spector P. E., 1985) Mentioned that the measurement of job satisfaction through pay, benefits, contingent rewards and etc. Job satisfaction can be minded by disparate considerations which include administration, supervision, policies, salary, and quality of life. Researchers identified in the researches that person-organization fit and person-job fit ought to be co-related to evaluate job satisfaction. 
Stress and dissatisfaction lead to high turnover rates. JS is the degree of contentment employees feel about their job, moreover, when as employee skills and abilities are equal to the work will move to increase the job satisfaction. Pay, security and promotions are lineally interconnected with job satisfaction. In Short, the Job satisfaction illustrates the difference between what people expect from the job and what they get in real whereas, normally, if the person has required skills to accomplish the responsibilities are considered to possess high person job fit. Various researchers put forward that, in general person-job fit, person-organization fit have significant relation with job satisfaction. In this respect, (Iqbal, 2012) Conducted research on impact of PJ-fit on job satisfaction, observed that no significant research directed in the Pakistani scenario and taking into consideration of educational institute (universities).The research examination hinged on quantitative data which was collected from disparate universities. Furthermore, SPSS software were used for analysis, the study variables were job satisfaction and job performance (Dependent variable) and person-job fit (Independent Variable), found that the responsibilities, assign task must meet with the competencies of the employees however, the tasks that unmatched with abilities will lead the way towards dissatisfaction. Similarly, (Sharon Ruvimbo Terera, 2014) revealed that reward has insignificant relationship with job satisfaction that means reward is not only the determinant of job satisfaction. However, the reward and retention have positive relationship additionally, it was expressed that job satisfaction and employee retention have positive significant relationship. The study utilised quantitative research design and 180 nurses were randomly selected. The data was analysed by Statistical Package for Social Science (SPSS), version 20.0. Correspondingly, (ASLAN1, 2019) examined how person-job fit affects p-o fit and job satisfaction in the perspective of bank in Adana province. The mediating variables were personjob fit, person-organization fit and job satisfaction. In addition, SPSS 21 and Amos program were used to examine the data. In this manner, stated that person-organization fit has both direct 
and indirect effect of person-job fit and job satisfaction. A related research conducted by (Atif Anis, 2011) investigated the relationship between employee retention, job satisfaction, perceived supervisory support and compensation by considering the organizational commitment as mediating variable in pharmaceutical industry in Pakistan. The total 450 questionnaires were filled out from employees of six pharmaceutical firms out of which 320 useful questionnaires were included for further analysis. The result concluded that organizational commitment has a strong and positive relationship with employee job satisfaction and employee retention. The study also specified that satisfied employee is more loyal with the organization therefore, employee is unlikely to switch job and work hard for the organization. Similarly, (Gul, 2018) (Kristof-Brown, 2015) noted in their studies that the person-job fit and job satisfaction have a positive significant relationship. Several authors have attempted to investigate on p-o fit, p-j fit and job satisfaction. Same way, (Caldwell, 1990) found a person-job fit positive relation with job performance, where 7 samples representing a variety of job and organization. According to Closely, (Datta.B. Pawase, 2013) observed that quantity of small and big have entered to pharmaceutical drug manufacturing which mediates job opportunities for marketing personnel and career growth, investigated on the role of person job fit and person organization fit on the job satisfaction, organization commitment and turnover intentions in the context of pharmaceutical firms in district Pune. Quantitative research methodology was used where sample size was restricted to medical representative working in district Pune. The job satisfaction and organization commitment were considered as dependent variables and person-job fit as independent variable. At last, concluded that job satisfaction and organization commitment are supreme variable. The study has revealed a positive association between person-job fit, job satisfaction. In the same manner, (Yi- Chang Lin, 2014) Found that the employee's positive affect had a positive effect on both their sense of well-being and job performance, and was a highly significant positive correlation between 
person job fit and well-being and both well-being person job fit had a positive effect on job performance Where the participants were 212 of 10 life insurance companies in Taiwan. Moreover, (Sethela June, 2011) Distributed 1500 questionnaire in which 300 respondents data were considered useful to analyse the result. The result demonstrated that significant positive relation, in addition, (Ambrose, 2008) conducted research on 73 organizations using a sample size of 304 individuals. Found that person organization ethical value fit relates to job satisfaction, commitment and turnover intensions, and for analysis, multiple regression model was used. However, (Silverthrone, 2004) conducted study in Taiwan which indicates that the person organization fit is a key element in both the level of job satisfaction that employees experience and also in their level of organizational commitment whether measured by an instrument or turnover rates. The fit plays a vital role in all kind of organizations. Similarly, (Chunjiang, 2011) demonstrated that the person-organization fit correlated to job satisfaction. In addition, a similar assertion was made by (Dubey, 2016) to thoroughly work on mediating role of need satisfaction and to investigate the relationship of P-O fit and job satisfaction, The simple consisted of 400 Nurses from different government and private schools and the study finding postulated that the person organization fit of nurses was positively correlate with significantly predicted the job satisfaction. Moreover, (Bilal Afsar, 2016) expressed that person-organization fit associated with organization citizenship behaviour. According to (MinJi Je, 2010) the collected data from the restaurant at Kyunggi, A total of 210. The result indicated that the person-organization fit has positive connection to occupational commitment and organizational commitment and organizational commitment. The person-job fit also found significant relation with organizational commitment, as far as (Smith, 1969)". (Muthuvelooa, 2020) Attempted to investigate on human resources management practices, personorganization fit and job satisfaction from the nurse's perspective which are associated with private sector hospital in Jordon. Data collected directly using structural questionnaire from 
274 responded through convenience sampling technique, in addition, the data was analysed with PLS-SEM, findings specified that person-organization fit influence on Job satisfaction , in the same way, The Author, (Osman M Karatepe, 2016) obtained data from hotel employees, the result demonstrated that person-job fit connected with work engagement.

\section{RESEARCH METHODOLOGY}

\section{Research Design}

The reason of the research is to analyse the impact of Person-Job fit, person organization fit and Job satisfaction. The paper adopted a descriptive survey design which is primary data. The method of the research is mono method and the examination of the study based in quantitative research and is used explanatory as it is theory based testing. The scope of the study is applied as it is applicable in the business Manufacturing sector in Karachi. In addition, the approach is deductive and it is from general to specific, as data is collected only from Aspin Pharma Karachi. The time horizon is cross sectional as gathered data from business organizations in Pakistan. The data collection approach is primary. The type of researcher investigation is correlational as there is no interference, lastly, the study setting is based on the natural environment.

\section{Procedure}

The study is the cross-sectional study and used a quantitative approach through descriptive statistics to measure the multi-dimension of employee satisfaction, person job fit and person organization fit.

\section{Population}


Aspin Pharma is located in Karachi, the total population of the study was 313 in which 173 selected as a sample size, further, and the respondents of the study were employers of Aspin Pharma Company.

\section{Sample and Sampling Method}

The study is restricted to Aspin Pharma in 2015 associated with OBS group acquire Janssen, now pharma has achieved scale of efficiency with GNP complaint manufacturing facility and a team of dynamic professional has 313 employees across of its location. The data collection has done through non-probability (convenience sampling). The survey was conducted in all department of Aspin Pharma by visiting there. The sample size is 173 this means 173 or more measurements/ service could be needed to have confidence level of $95 \%$ that the real value can be within 5\% of the measured surveyed (Raosoft, 2020)

\section{Instrument Selection}

A questionnaire is developed to gather the data from the respondents regarding Job satisfaction, Person Job fit and Person Organization. Moreover, the survey questionnaire was adopted from previous similar studies of (Spector, 1985) (Chhabra B. , 2015) the research tool used for the study was scaled questionnaire which includes the following types of scales:

Likert Scale [Strongly Disagree/Disagree/Neutral/Agree/Strongly Agree]

\section{HYPOTHESIS}

$H 1=$ Person-Job Fit has a significant relationship with Job satisfaction.

$H 2=$ Person-Organization Fit has a significant relation with Job satisfaction. 


\section{DATA ANALYSIS}

\section{Table 1 Respondent Profile}

The data was collected from employee of Aspin Pharma firm through questionnaires, the data was organized and the table 1 shows the profile of the respondent where $84 \%$ were male and 15 were female. Further, a sizable portion of employees were masters.

\begin{tabular}{|c|c|c|c|c|}
\hline Factor & Respondent & Category & Frequency & Percentage\% \\
\hline Gender & 173 & $\begin{array}{l}\text { Male } \\
\text { Female }\end{array}$ & $\begin{array}{l}146 \\
27\end{array}$ & $\begin{array}{l}\text { Male }=\mathbf{8 4 . 4 \%} \\
\text { Female }=\mathbf{1 5 . 6 \%}\end{array}$ \\
\hline Age & 173 & $\begin{array}{l}18-25 \\
26-35: \\
35-45 \\
46-55 \\
56 \text { Above }\end{array}$ & $\begin{array}{c}18 \\
108 \\
47 \\
0 \\
0\end{array}$ & $\begin{array}{l}18-25=\mathbf{1 0 . 4 \%} \\
26-35=\mathbf{6 2 . 4 \%} \\
36-45=\mathbf{2 7 . 7 \%} \\
46-55=\mathbf{0 \%} \\
56 \text { Above }=\mathbf{0 \%}\end{array}$ \\
\hline Qualification & 173 & $\begin{array}{l}\text { Matric / O - level } \\
\text { Intermediate / A - level } \\
\text { Bachelors } \\
\text { Masters } \\
\text { Doctorate }(\mathrm{PhD})\end{array}$ & $\begin{array}{l}0 \\
10 \\
66 \\
86 \\
11\end{array}$ & $\begin{array}{l}\text { Matric } / \mathrm{O}-\text { level }=\mathbf{0 \%} \\
\text { Intermediate } / \mathrm{A}-\text {-level }=\mathbf{5 . 8 \%} \\
\text { Bachelors }=\mathbf{3 8 . 2 \%} \\
\text { Masters }=\mathbf{4 9 . 7 \%} \\
\text { Doctorate }(\mathrm{PhD})=\mathbf{6 . 4 \%}\end{array}$ \\
\hline Experience & 173 & $\begin{array}{l}\text { Less than } 1 \text { year } \\
1 \text { year to } 4 \text { years } \\
5 \text { years to } 10 \text { years } \\
11 \text { years to } 15 \text { years } \\
16 \text { years to } 20 \text { years } \\
21 \text { years or above }\end{array}$ & $\begin{array}{l}22 \\
86 \\
55 \\
55 \\
1 \\
1\end{array}$ & $\begin{array}{l}\text { Less than } 1 \text { year }=\mathbf{1 2 . 7 \%} \\
1 \text { year to } 4 \text { years }=\mathbf{5 1 . 4 \%} \\
5 \text { years to } 10 \text { years }=\mathbf{3 1 . 8 \%} \\
11 \text { years to } 15 \text { years }=\mathbf{2 . 9 \%} \\
16 \text { years to } 20 \text { years }=\mathbf{6 \%} \\
21 \text { years or above }=\mathbf{6 \%}\end{array}$ \\
\hline
\end{tabular}


Table 2: Descriptive Analysis

\begin{tabular}{|c|c|c|c|c|c|}
\hline No. & Variable & Questions & $\begin{array}{l}\text { Respondents } \\
\text { (N) }\end{array}$ & Mean & $\begin{array}{l}\text { Standard } \\
\text { Deviation }\end{array}$ \\
\hline \multicolumn{6}{|c|}{ Variable: Person-Job Fit (IV) } \\
\hline 1 & PJF 1 & Personal Skills & 173 & 4.00 & .610 \\
\hline 2 & PJF2 & Skills and abilities & 173 & 4.06 & .753 \\
\hline 3 & PJF3 & Education & 173 & 3.91 & .809 \\
\hline \multicolumn{6}{|c|}{ Variable: Person-Organization Fit (IV) } \\
\hline 4 & POF1 & Values & 173 & 3.21 & 1.207 \\
\hline 5 & POF2 & Organization's Culture & 173 & 3.22 & 1.140 \\
\hline 6 & POF3 & Value and Culture & 173 & 3.26 & 1.076 \\
\hline 7 & POF4 & Organization offers job & 173 & 3.44 & .917 \\
\hline 8 & POF5 & Attributes & 173 & 3.45 & .961 \\
\hline 9 & POF6 & Want from Job & 173 & 3.55 & .918 \\
\hline \multicolumn{6}{|c|}{ Variable: Job Satisfaction (DV) } \\
\hline 10 & JS1 & Salary & 173 & 3.91 & .834 \\
\hline 11 & JS2 & Pleasure of job & 173 & 3.92 & .892 \\
\hline 12 & JS3 & Pride of job & 173 & 3.80 & .860 \\
\hline 13 & JS4 & Satisfaction of job & 173 & 3.87 & .921 \\
\hline
\end{tabular}

The discoveries acquired from the survey have been assessed by mean (X) and standard deviation (S.D) so as to decide the respondents score level of perception on job satisfaction, we used multiple regression analysis. Further, we determine the mean and standard deviation to check the tendency of the research. 
Table 3: Construct Reliability and Validity

\begin{tabular}{|l|l|l|l|}
\hline & Cronbach's & $\begin{array}{l}\text { Composite } \\
\text { Alpha }\end{array}$ & $\begin{array}{l}\text { Average Variance Extracted } \\
\text { (AVE) }\end{array}$ \\
\hline Job Satisfaction & 0.910 & 0.937 & 0.787 \\
\hline Person-Job Fit & 0.945 & 0.965 & 0.902 \\
\hline Person- & 0.925 & 0.942 & 0.729 \\
\hline
\end{tabular}

\section{Composite Reliability}

The accuracy of questionnaire results is indicated by reliability. For a similar target group, it will offer a comparable outcome at any stage the questioner reuses the questionnaire. It shows that the survey's internal accuracy and repeatability are strong. Maintaining a strategic distance towards unfairness in study is the primary indicator for unswerving consistency. It continues to be strengthened in this way by checking the pursuit procedure and investigation, as is achieved by using various analysis and review methods or various researchers. This often integrates the exploration's reliability and validity.

Using composite reliability, the reliability of the measurement instrument was assessed. All values were over the standard value usually used, i.e., 0.70. This is the agreed value set for reliability. The level of constancy between different variables could be used to estimate reliability.

According to (Hair, 2006) the accepted reliability of the indicators must be above 0.70 , the values of all variables in the above table are above 0.7 , which indicates that the data is accurate and reliable. 


\section{Average Variance Extracted (AVE)}

Average variance extracted is evaluated in order to check the convergent validity. According to (Fornell, 1981) if the variance extracted value is greater than 0.5 then convergent validity is established but less than 0.5 termed as less effective for the study. The table 4.3 clearly indicates that variance extracted values are above 0.5 of all the variables including person-job fit, person-organization fit and job satisfaction which shows questions of variables were perfect.

\section{Validity}

Three type of validity is tested. Firstly, Discriminant validity is tested then construct validity and at last, Convergent validity. Discriminant validity is checked with the help of FornellLarcker Criterion. Moreover, construct validity is checked with the help of factors loading however, convergent validity is checked with the help of average variance extracted.

\section{Table 4: Discriminant Validity}

(Fornell-Larcker Criterion)

\begin{tabular}{|l|l|l|l|}
\hline & Job Satisfaction & Person-Job Fit & Person-Organization \\
& & Fit \\
\hline Job Satisfaction & $\mathbf{0 . 8 8 7}$ & & \\
\hline Person-Job Fit & 0.788 & $\mathbf{0 . 9 5 0}$ & \\
\hline Person-Organization Fit & 0.765 & 0.827 & $\mathbf{0 . 8 5 4}$ \\
\hline
\end{tabular}

The concept of discriminant validity in introduced by (Fiske, 1959) Discriminant validity evaluations are actually non-related to ideas or measurement system that are not necessarily correlated with other test. (Henseler, 2016) through their debate on determining test validity, (Fornell, 1981) suggested the square of average variance extracted of each variable can be used to determine the discriminant validity. Although there is no scale parameter for discriminant validity, a response less than 0.85 means that the measurements are likely to have discriminant 
validity while, above 0.5 shows that discriminant validity is not exist, however, the findings of variables are greater than 0.85 , therefore, the table 4.4 shows that the questions are valid and the discriminant validity can be claimed among them.

\section{DISCUSSION, CONCLUSION, RECCOMENDATION}

\section{Discussion}

The present study aimed to examine the impact of Person- Job Fit and Person-Organization Fit on Job satisfaction. The findings, based on the sample size of employee from the pharmaceutical Company, (Aspin Pharma), illustrates that the Person-Job Fit is positively associated to Job Satisfaction, Proving H1. The result also confirmed that in addition to link between Person-Organization Fit on Job Satisfaction has a positive significant relation.

In summary, the result indicates that the employee whose skills, knowledge, attributes, culture, norms do not match with job requirement are likely to be dissatisfied than the employee who have better person-job fit leads to be more satisfied with job that in turn result in lower dissatisfaction however, person-organization fit also affect the job satisfaction when organization's culture and values do not match with employee culture, value and personality.

\section{Conclusion}

The study was intended to investigate the impact of person-job fit and person-organization fit on job satisfaction with in the manufacturing sector Aspin Pharma (Pharmaceutical Industry) of Pakistan. Globally, several literatures are available about Job satisfaction yet within the context of Pakistan, a limited portion of researches are available, especially, this is very first research conducted in Aspin Pharma industry. Above literature review indicates that personjob fit and person organization fit have positive impact on Job satisfaction, in this manner, this study result shows that person job fit has a significant relation with job satisfaction and personorganization fit has a significant relation with job satisfaction. 
Findings of current study suggested that organizational leaders should not neglect the personal attributes of their employees. Employees whose personal attribute and values are unmatched with job requirements likely to be dissatisfied. It is suggested to organizational leader that must be worried and careful while hiring the right person according to the attributes required performing the job. Organizational leaders must think about the employee culture and norms. The fit between organizational culture and person culture must match together. Focusing overall employee fit may increase job satisfaction.

\section{Recommendations}

Several recommendations for future research based on findings of the study, firstly, some efforts must be made in order to confirm the result of current research between other samples and populations. Secondly, the theoretical model of the study has found evidence of an association among person-job fit, person-organization fit with job satisfaction, it is also possible other variables can affect this fit therefore, other organizational variables can be used to determine the impact of job satisfaction. Finally, this study is beneficial especially for the HR managers, and other research methodologies. 


\section{REFERENCES:}

Ambrose, M. L. (2008). Individual Moral Development and Ethical Climate- The influence of Person Organization fit and Job attitudes. Business Ethics , 323-333.

Aslan1, D. H. (2019). "Mediating Role of Person-Organization Fit In Person-Job Fit's Effect On Job Satisfaction ". Journal of Economics and Administrative Sciences , 275-284 .

Atif Anis, K.-u. R. (2011). Impact of Organization Commitment on The Job Satisfaction and Employee Retention in Pharmaceutical Industry. African Journal of Business Management, Vol. 5(17), pp. 7316-7324.

Bilal Afsar, Y. F. (2016). Person-Organization Fit, Perceived organizational Support, and Organizational Citizenship Behavior: The role of Job Embeddedness. Human Resources in hospitality and Tourism, 15(15), 252-278.

Caldwell, D. F. (1990). Measuring Person Job Fit with a Profile . Comparison Process . Applied Psychology .

Chang-qin Lu, H.-J. W. (2014). Does work engagement increase person-job fit? The role of Job crafting and job insecurity . Vocational Behavior , 84(2), 142-152.

Chhabra, B. (2015). Person-Job fit: A mediating role of job satisfaction and organization commitment . Indian journal of industrial relations .

Chunjiang, Y. (2011). The Effect of Person Organization Fit on Job satisfaction and Turnover Intention .

Datta, B., \& Pawase, D. P. (2013). "Role of P-E fit on Job Satisfaction of Medical Representatives". International Journal of Engineering Research and Applications (IJERA), 19-22 .

Dubey, R. C. (2016). Relationship between Person Organization and Job satisfaction: Mediating Role of Need Satisfaction. International Journal of Education and Management, 170-174. 
Farooquia, M. S., \& Nagendrab, D. A. (2014). "The Impact of Person organization Fit on Job Satisfaction and Performance of the Employees". Symbiosis Institute of Management Studies Annual Research Conference (SIMSARC13), 122 - 129 .

Fiske, C. A. (1959). Wikipedia the free encyclopedia. Retrieved from Wikipedia: https://en.wikipedia.org/wiki/Discriminant_validity

Fornell, C. \&. Larcker (1981). Structural equation models with unobservable variables and measurement error: Algebra and statistics., 382-388.

Gul, H. U. (2018). Does the effect of power distance moderate the relation between person environment fit and job satisfaction leading to job performance? Evidence from Afghanistan and Pakistan. Future Business Journal, 4(1): 68-83.

Hair, J. F. (2006). Multivariate data analysis. Upper saddle River.

Henseler, J. (2010). On the convergence of the partial least squares path modeling algorithm2E. Computational statistics, 25(1), 107-120.

Henseler, J. H. ((2016).). . Using PLS path modeling in new technology research: updated guidelines. . Industrial management \& data systems.

Iqbal, M. T. (2012). "The Impact of Person Job Fit on Job Satisfaction and its Subsequent Impact on Employees Performance". Mediterranean Journal of Social Sciences , 20392117.

Iqbal, M. T. (2012). "The Impact of Person Job Fit on Job Satisfaction and its Subsequent Impact on Employees Performance". Mediterranean Journal of Social Sciences.

Kristof-Brown, A. L. (2015). Consequences Of Individuals’ Fit At Work: A Meta-Analysis of Person-Job, Person-Organization, Person-Group, And Person-Supervisor Fit,. Personnel Psychology, 58(2): 281-342. .

Mao, C. (2014). "The Impact of Person-Job Fit on Job Satisfaction: The Mediator Role of Self Efficacy. Springer Science +business Media Dordrecht . 
Mete, E. S. (2016). The relationship between Organizational Commitment, Organizational identification person organization fit and job satisfaction. International Review of Management of and Business Research , 2306-9007.

Min-Ji Je, Y. G. (2010). Effects of Person Organization Fit and Person Job Fit on Occupational Commitment, Organizational Commitment and Turnover intention of Cooks. Culinary Science and Hospitality Research , 16(5),50-63.

Muthuvelooa, S. A. (2020). "Human resource management practices and person-organization fit towards nurses' job satisfaction . Graduate School of Business, Universiti Sains Malaysia, 11800 Penang, Malaysia .

Osman M Karatepe, G. K. (2016). Service employee Fit work Family Conflict, and Work Engagement . Service Marketing .

Raosoft. (2020, Dec 15). Sample size calculator. Retrieved from Rao soft: http://www.raosoft.com/samplesize.html

Sethela June, R. M. (2011). The Relationship Between Person Job Fit and Job Performance: A Study Among The Employees Of The Service Sector SMEs in Malaysia. International Journal of Business, Humanities and Technology, 1 (2) 95-105.

Sharon Ruvimbo Terera, H. N. (2014). The Impact of Rewards on Job Satisfaction and Employee Retention . Mediterranean Journal of Social Sciences, Vol 5 No 1 E-ISSN 2039-2117.

Silverthrone, C. (2004). The impact of Organization culture and person-organization fit on organizational commitment and job satisfaction in Taiwan. The leadership and Organization Development journal www.emeraldinsight.com/researchregister, 01437739.

Smith, H. (1969). "The measurement of job satisfaction in work and retirement. Chicago: randMCNALLY. 
Spector. (1985). "Measurement of human service staff satisfaction . American journal of commission, 693-713.

Spector, P. E. (1985). "Measurement of Human Service Staff Satisfaction". American Journal of Community Psychology, 13 (6) 693.

Yi- Chang Lin, C. Y.-C. (2014). The Effect of Positive affect Person-Job Fit and Well-being on Job performance. Social Behavior and Personality: An International Journal, 42(9),1537-1547. 